Session 2315

\title{
A New Format for Continuing Education- Professional Development Lectures
}

\author{
Francis M. Thomas, Steven L. McCabe \\ Department of Civil and Environmental Engineering \\ University of Kansas
}

\begin{abstract}
The Civil and Environmental Engineering Department at the University of Kansas has developed a series of lectures for practicing engineers. These have been named the "Professional Development Series."
\end{abstract}

The Civil and Environmental Engineering Department at the University of Kansas has conventional undergraduate and graduate programs. The Department offers Bachelors, Masters, and Ph.D. degrees on the main campus of the University of Kansas in Lawrence. The Department also offers a masters level graduate program at the Edwards Campus which is in the Kansas City metropolitan area. In addition to conventional degree programs, the Department offers, on a yearly basis, a series of one-day technical programs that are attended by practicing engineers.

These programs have addressed a long-standing need for continuing education in the engineering community, but in recent years, engineers have requested a different form of continuing education than traditionally had been offered. There is a need for information to be available to all engineers, not just those seeking advanced degrees. The request has been for continuing education material that would be available in a single lecture format, rather than a semester-long format as is required for graduate courses.

In response, the Civil and Environmental Engineering Department at the University of Kansas has developed a series of technical lectures. Each of the lectures is two hours in length and is presented by a different faculty member. The lectures present an overview of various current aspects of civil and environmental engineering. The participants attending the lectures can select and attend only those lectures that are of interest to them. This series of lectures is entitled the "Professional Development Series in Civil and Environmental Engineering." The series was first presented in the spring semester of 1999. Due to its success, a new series was offered during the spring semester of 2000. In response to the needs of engineers in other disciplines, the 2001 series has been expanded to include topics from other engineering disciplines.

\footnotetext{
"Proceedings of the 2001 American Society for Engineering Education Annual Conference \& Exposition Copyright (C) 2001, American Society for Engineering Education”
} 
This paper will present details of the Professional Development Series. Items discussed will be the content of the lectures, the benefits to the engineering community and the Civil and Environmental Engineering Department, the manner in which the series was developed, and an assessment as to the success of the series.

\section{Introduction}

The Civil and Environmental Engineering Department at the University of Kansas has addressed the continuing education requirements of the engineering community in a variety of ways. The department grants Bachelor degrees, various Masters degrees and Ph.D. degrees on the Lawrence campus and also grants Masters degrees at the evening program located at the Overland Park, Kansas Edwards Campus, in suburban Kansas City. In addition to the degree programs, the department sponsors three, one-day technical conferences each year. The conferences are: 1) the structural engineering conference, 2) the environmental engineering conference, and 3) the asphalt paving conference. The planning of each of these conferences involves the faculty and representatives of local industry. The conferences present invited speakers as well as faculty presentations that address the needs of the respective engineering participants.

The engineering community has, in recent years, requested a different form of continuing education. The degree programs do not address the needs of those who do not desire an advanced degree. The conferences address a different need than the degree programs, but they present a scheduling problem in that it is necessary to miss an entire day of work in order to attend the conference. This can be difficult, in some cases, due to project deadlines, etc. In an attempt to address the need for additional continuing education for the engineering community, the Civil and Environmental Engineering department has introduced a series of Professional Development Lectures.

\section{Civil and Environmental Engineering Faculty}

The Civil and Environmental Engineering faculty consists of twenty-five members with a wide range of expertise. The main groups in the department are structural, mechanics, environmental, geotechnical, transportation, construction, and water resources. In addition to these groups individual faculty members have specialization areas. These areas include, but are not limited to composite and concrete materials, artificial computer intelligence, and high-temperature pipe stress analysis. This range of knowledge makes the concept of the professional lectures attractive because a wide variety of topics can be addressed in the presentations. Several faculty members also have consulting and industrial experience, allowing them to understand the needs of practicing engineers.

III. Market for Professional Development Lectures

\footnotetext{
"Proceedings of the 2001 American Society for Engineering Education Annual Conference \& Exposition
} Copyright 2001, American Society for Engineering Education" 
The University of Kansas is located near both Kansas City, Missouri and Topeka, Kansas. Kansas City is the home of a number of large consulting firms, among these are Burns and McDonnell Engineering Company, HNTB Corporation, and Black and Veatch. There are also a large number of smaller consulting firms in both Topeka and Kansas City. Kansas City represents a center with one of the highest per capita populations of civil engineers in the United States. In addition to the consulting firms, both the Kansas and Missouri Departments of Transportation have offices in the Kansas City and Topeka areas. This concentration provides an excellent pool of engineers and, therefore, makes the concept of the professional development lectures attractive to the Civil and Environmental Engineering Department and to the engineering community.

\section{Creation of the Professional Development Lectures}

Once the need for a new form of continuing education was recognized, representatives of the Civil and Environmental Engineering Department and representatives of the local engineering firms met and identified specific topics that would be of value to local engineers. These discussions also led to the lecture format. Each lecture was two hours in length and was given on Monday afternoons from 4:00 PM to 6:00 PM. A total of twelve lectures were planned and given over the period beginning January 25, 1999, and ending April 19, 1999. Burns and McDonnell Engineering Company of Kansas City, Missouri provided an auditorium for the lectures in their international headquarters building.

Complete sets of lecture tickets were sold to companies who wanted their employees to attend. The cost for each two-hour lecture was $\$ 40.00$. The format allowed employees to select only those lectures useful to them. Tickets for individual lectures were also available. Several companies bought tickets for the entire series and distributed them to different individuals in their company according to the interest of the employee. Thus a company could buy a group ticket and have a number of people attend and benefit from the lectures.

The concept of the lectures was developed late in the year 1998. It did not allow time to advertise. In an effort to overcome this timing limitation, a number of retired alumni from the department Advisory Committee volunteered to contact several companies in the area and inform them of the plans for the lecture series and to encourage the companies to buy a group of tickets for their employees. The companies then, in turn, distributed the tickets to individuals who would most benefit from the material in each lecture.

The following lectures were presented during the first series in the spring of 1999.

January 25, 1999

Material Properties as Related to the Behavior of Structural Steel Details

February 1, 1999 Intelligent Transportation Systems

February 8, 1999 High-Temperature Pipe Stress Analysis

February 15, 1999 Upcoming Changes In the ACI 318 Building Code for 1999.

\footnotetext{
"Proceedings of the 2001 American Society for Engineering Education Annual Conference \& Exposition
} Copyright 2001, American Society for Engineering Education" 
February 22, 1999

March 1, 1999

March 8, 1999

March 15, 1999

March 29, 1999

April 5, 1999

April 12, 1999

April 19, 1999
High-Strength Concrete

GIS for Geotechnical Engineering Applications

Water Treatment Plant Design and Operation to Meet the

Enhanced Coagulation and Softening Requirements of the Stage-1 D/DBP Rule.

Improving the Effectiveness of Bioremediation Processes Through

Better Biology

Composites for Structural Applications

An Overview of Floodplain Analysis

Performance Based Design for Earthquake Resistant Structures in

Regions of Moderate Seismicity

Current Problems in Air Pollution

V. Evaluation of 1999 series

The lectures were judged by the participants to be a success. An evaluation form was circulated after each lecture. The attendees evaluated the presentation and also the significance of the material in each lecture. The total number of attendees for all twelve lectures was 817 . The maximum attendance (126) was on the February 22, 1999 at the high-strength concrete lecture and the smallest attendance (17) was on the March 8 lecture at the Water Treatment Plant Design lecture. The attendance did not appear to depend on the quality of the lecture, but rather on the number of people working in the area that the lecture addressed.

The Professional Development Series has proven to be a win-win situation for both the Civil and Environmental Engineering Department and the engineering companies and their employees. Several attending the lectures have since enrolled in evening Masters degree courses that are offered at the University of Kansas Edwards campus. The Department also earned needed revenue that was shared, in part, with those faculty members presenting the lectures. A parttime secretary was hired with the revenue that benefited the entire Department. The companies benefited because they had current state-of-the-art information presented to their employees. The engineers benefited by learning new information and they also received 2 professional development hours (PDH) for each lecture attended. The PDH hours can be used to keep their professional license registration current.

VII Spring 2000 Professional Development lectures.

A second series of lectures was presented during the spring 2000 semester. As in the first series, the presentations were planned to respond to the needs of the engineering community. A new set of topics was selected and, for the most part, a different group of faculty presented the lectures. By using different faculty, the workload was distributed and a broader exposure of the faculty was presented to the engineering community. The attendance increased as was anticipated because a larger number of companies participated and the plans were made further in advance, thus allowing time for potential participants to learn of the lectures.

\footnotetext{
"Proceedings of the 2001 American Society for Engineering Education Annual Conference \& Exposition Copyright 2001, American Society for Engineering Education"
} 
The lectures presented during the spring 2000 series are listed below.

January 31,2000

February 7, 2000

February 14, 2000

February 21, 2000

February 28, 2000

March 6, 2000

March 13, 2000

March 27, 2000

April 3, 2000

April 10, 2000

April 17, 2000

April 24, 2000
Fatigue Design of Steel Structures

Design of Reinforced Concrete Members for shear

Understanding Superpave

Web Based Project Management

Experimental Design, Hypothesis, Testing, Univariate/Multivariate Methods

Application of Vibration Isolation

Fastening to Concrete

Design Highways for Safety

Hydrologic Modeling for Flood Studies

Taste and Odor Control in Public Water Supplies

Wetland Permitting

Bioremediation Design Fundamentals

VIII Evaluation of the Spring 2000 series

The attendance of the 2000 series, as anticipated, increased over the 1999 series attendance. The average attendance was 96 per lecture with a total attendance of 1156 for the series. As in the first year of the series, there was a wide range of attendance depending on the lecture topic. The high attendance was 169 for the lecture on "Fastening to Concrete" and the low attendance was 39 on the lecture on "Taste and Odor Control in Public Water Supplies".

IX. Spring 2001 Professional Development lectures.

A new set of lectures has been planned for the spring of 2001. In order to appeal to a larger group of engineers, the scope of the topics has been broadened to include lectures beyond traditional civil engineering topics. Lectures on engineering ethics, global positioning, web management, and construction management will be presented.

The lectures planned for the spring 2001 series are listed below.

January 22, 2001

January 29, 2001

February 5, 2001

February 12, 2001

February 19, 2001

February 26, 2001

March 5, 2001

March 12, 2001

March 26, 2001
Frame Stability - Practical Issues for Engineers

GIS Applications in Civil Engineering

GIS:Basic Tools for Hydrologic Analysis

Web Based Project Management- One Viewpoint

Professional Ethics

Construction Claims Analysis

Air Pollution and the Transportation Industry

Wetlands and Mitigation Banking

Web Based Project Management- Another Viewpoint

"Proceedings of the 2001 American Society for Engineering Education Annual Conference \& Exposition Copyright 2001, American Society for Engineering Education” 
April 2, 2001

April 9, 2001

April 16, 2001
GIS Applications in Flood Plain Analysis

Risk Assessment and Management

Concrete Durability

X Summary

The Professional Development Series provides a new means of providing continuing education to practicing engineers in the greater Kansas City - Topeka area. It provides a transfer of current state of the art information to the engineers thus allowing them to remain current in their professional development. The lecture series also provides the opportunity for the department to attract qualified candidates to the masters degree programs on both the Lawrence and Edwards campus programs. The series has proven to be good for the practicing engineers, the department and the faculty.

The 2001 series opens up the topics to attract not only civil engineers but engineers from other disciplines and other technical professionals. It is anticipated that the expanded format will prove to increase the success of the series which has already been judged a success in previous years.

FRANCIS M. THOMAS

Francis Thomas is the John and Winfred Sharp Distinguished Professor of Civil and Environmental Engineering at the University of Kansas. He earned a Ph.D. in Theoretical and Applied Mechanics from the University of Illinois. He has taught undergraduate and courses in Engineering Mechanics and has served as a consultant to industry with a specialization in structural dynamic analysis and high temperature piping stress analysis.

STEVEN L. McCABE

Steven L. McCabe is professor and Chair of the Civil and Environmental Engineering Department at the University of Kansas. He earned a Ph.D. from the University of Illinois in Civil Engineering. He teaches undergraduate and graduate courses in structural design and analysis. He is actively involved in research in concrete bond behavior and seismic design.

"Proceedings of the 2001 American Society for Engineering Education Annual Conference \& Exposition Copyright 2001, American Society for Engineering Education" 